\title{
Consolidation of Business Collections
}

Announcement has recently been made in the public press of the projected fusion of business literature now contained in the Boston Public Library and the Harvard Business Library. These collections, together with that of The Business Historical Society and others, it is now planned to amalgamate into one unified collection of business material in the new Baker library building of the Harvard Business School.

The combination of these various resources will, it is hoped, increase the strength and usefulness of the ultimate collection manifold because of the fact that one large collection, reasonably complete, is worth to a student many times an equal amount of material in a number of small collections widely distributed.

These amalgamations will take place this spring or summer, and it is hoped that by fall a students' Mecca for members of this Society will be established at our headquarters in Cambridge.

\section{Letter to the Editor}

The Editor of the Bulletin, Business Historical Society,

Dear Sir:-

I was much interested in the contents of your interesting Bulletin, which $I$ have just seen. There is undoubtedly a great need today for the preservation and collection of material relating to business and business history, a need which the efforts of your Society should do much to meet. As the author of several volumes on varying aspects of business, I can testify to the great value of such deposits of primary material as that being collected by the Business Historical Society - deposits which are a necessity for research workers and writers but which hitherto often have been either inaccessible or absolutely non-existent.

Very truly yours,

(Signed) Walter S. Hayward. 